\title{
Microsieve Supporting Palladium-Silver Alloy Membrane and Application to Hydrogen Separation
}

\author{
Hien Duy Tong, F. C. Gielens, J. G. E. Gardeniers, Henri V. Jansen, J. W. Berenschot, Meint J. de Boer, J. H. de Boer,
} Cees J. M. van Rijn, and Miko C. Elwenspoek

\begin{abstract}
A submicron thick and defect-free palladium-silver (Pd-Ag) alloy membrane is fabricated on a supporting microsieve by using microfabrication techniques. The microfabrication process also creates a robust wafer-scale membrane module, which can easily be inserted into a membrane holder to have gas-tight connections to the outer world. The microfabricated membrane demonstrated high separation fluxes of up to $4 \mathrm{~mol} \mathrm{H}_{2} / \mathrm{m}^{2} \cdot \mathrm{s}$ with a minimal selectivity of 1500 for hydrogen over helium $\left(\mathrm{H}_{2} / \mathrm{He}\right)$ at $450{ }^{\circ} \mathrm{C}$ and $83 \mathrm{kPa} \mathrm{H}_{2}$ retentate pressure. The present membrane has great potential for hydrogen purification and in applications like dehydrogenation chemistry. In addition, the presented technology can be used to fabricate other kinds of ultrathin but strong and defect-free membranes to set up new applications.

[1235]
\end{abstract}

Index Terms-Hydrogen separation, membrane module, membrane reactor, microfabrication technology, Pd-Ag membrane, SiN microsieves, $\{110\}$ wafers.

\section{INTRODUCTION}

\section{A. Hydrogen Applications and Selective Pd-Based Membranes}

Hydrogen is extensively used in many different industrial sectors [1]-[6]. Currently, the hydrogen industry is not so much focused (yet) on the production or use of hydrogen as an energy carrier or a fuel for energy generation. Rather, for instance in the US, the nine million tons of hydrogen produced each year are used mainly for petroleum refining, metals and electronics processing. The processes to produce gasoline and diesel fuels, such as the breakdown of heavier crude oils and the removal of sulphur, are major users of hydrogen. The production of ammonia, used to make fertilizers, also consumes large amounts of hydrogen. Therefore, hydrogen can be considered one of the most important industrial chemicals.

The depletion of crude oil, natural gas and fossil fuel in combination with the stricter rules on environmental regulations may make hydrogen a serious alternative clean energy carrier in future [2]-[6]. In this scenario, hydrogen is obtained from different resources and used to feed fuel cells and vehicles. By using hydrogen as the energy carrier, two major energy

Manuscript received December 30, 2003; revised June 16, 2004. This work was supported by STW (Dutch Technology Foundation), ABB Lummus Global Inc., DSM, and Aquamarijn. Subject Editor G. B. Hocker.

H. D. Tong, J. G. E. Gardeniers, H. V. Jansen, J. W. Berenschot, M. J. de Boer, J. H. de Boer, and M. C. Elwenspoek are with the MESA+ Research Institute for Nanotechnology, University of Twente, 7500 AE Enschede, The Netherlands (e-mail: T.Hien@el.utwente.nl).

F. C. Gielens is with the Department of Chemical Engineering and Chemistry, Eindhoven University of Technology, 5600 MB Eindhoven, The Netherlands.

C. J. M. van Rijn is with the Aquamarijn Micro Filtration B.V., 7201JE Zutphen, The Netherlands.

Digital Object Identifier 10.1109/JMEMS.2004.839005 challenges that confront society today are expected to become solved: 1) reducing our dependence on petroleum and fossil resources, and 2) reducing greenhouse gas emissions. Although many technological and economical challenges remain to be solved still, it has been predicted that hydrogen will be used as one of the major energy carriers in coming decades [2], [4], [6].

Although the most abundant element in the universe, on Earth hydrogen is mostly found in chemical compounds. Molecular hydrogen is produced from sources like water, biomass, or fossil fuels. Chemical reactions are therefore necessary to break apart the hydrogen bonds in these compounds and release the hydrogen; in doing so generally a multicomponent gas mixture is formed. To have hydrogen with high purity for the end-uses, the gas mixture is treated with several separation techniques, like pressure swing adsorption or filtration using of porous or nonporous membranes [2]. Among these methods, separation and purification of hydrogen by means of dense palladium (Pd)based membranes is of great importance and interest, because the technology is able to provide a high hydrogen separation flux with very high selectivity [7]-[20]. In most cases, Pd is alloyed with silver (Ag) to overcome the well-known problem of hydrogen embrittlement [7]-[9].

The existing Pd-based membranes can be mainly classified into two types, according to the structure of membrane: 1) selfsupporting Pd-based membranes and 2) composite structures composed of thin Pd-based layers on porous supports. Most self-supporting Pd-based membranes are commercially available in the form of tubes or foils, fabricated by fine metallurgical methods. These membranes have an adequate mechanical strength and are available in forms that are easily integrated into a separation setup. They are, however, relatively thick $(50 \mu \mathrm{m}$ or more) [10], [11]. The hydrogen flux, being inversely proportional to the thickness of the membrane, through such membranes is therefore limited. Besides this, thick Pd membranes are expensive, inhibiting their application for large-scale chemical production. For practical use, it is therefore necessary to develop separation units with a reduced thickness of the Pd layer.

In the last decade, a substantial research effort has been carried out to achieve higher fluxes by depositing thin layers of Pd or Pd alloys on porous supports like ceramics or stainless steel [12]-[20]. This method has turned out to be feasible, however to make submicron thick, defect-free separation membranes is difficult, due to the fact that commercially available porous supports are likely to be supplied with imperfections like particulates on the substrate, nonuniformities in pore size, etc. Due to this, the metal films do not cover up the supports completely [13], [14], [18], [19], [21]. For instance, Roa et al. deposited 
a $10 \mu \mathrm{m}$ thick $\mathrm{Pd}-\mathrm{Cu}$ film on a porous $\gamma$-alumina (nominal pore size of 5-50 nm) and reported that their membrane was not defect-free due to the imperfections of the initial supports [19]. Because of hydrogen molecules is small, the presence of only a few defects (for example, a total defect diameter of $0.5 \mu \mathrm{m}$ per $\mathrm{cm}^{2}$ of membrane surface) already significantly deteriorates the membrane selectivity.

An additional problem is that in order to have adequate mechanical strength, relatively thick porous supports have to be used, of the order of a few mm, which again leads to a considerably high mass transfer resistance, therewith limiting the separation flux through the membranes [17].

Recently, using very precise techniques to repair the surface of commercially available supports [21], [22], in combination with deposition methods with improved pore coverage [15], [22], thin membranes with a reasonably high selectivity for hydrogen have been demonstrated. For instance, Nam et al. reported a selectivity above 3000 for $\mathrm{H}_{2}$ over $\mathrm{N}_{2}$ for a less than $2 \mu \mathrm{m}$ thick Pd-Cu membrane, which was deposited by a vacuum electrodeposition method on porous stainless steel [22]. However, the reported repair procedures [15], [22] are complicated and time consuming, which limits batch production.

To avoid the initial surface imperfections, Bredesen and Klette deposited Pd alloy films on bare, atomically smooth silicon wafers and peeled off and transferred the deposited films to other supports to form membranes [23]. However, perfect transfer is crucial to obtain defect-free, submicron thick membranes, which is not an easy task.

In conclusion, it can be said that although there has been considerable progress in the field of membrane engineering in the last decade, a method to fabricate thin and defect-free Pd-based membranes (preferably submicron thick) on supports with a low mass transfer resistance is still very desirable.

\section{B. A New Membrane Fabrication Approach Using Microfabrication Technology}

Microfabrication techniques, originally developed for semiconductor technology and extended to micro-electromechanical systems [24], are increasingly used in different fields of chemistry and biotechnology [25]-[29]. By a combination of miniaturization and integration of components like sensors (e.g., for temperature and flow), heaters, mixers, valves, pumps etc. into one system, microchemical systems have been developed that have capabilities exceeding those of conventional systems [25]-[32]. For instance, in addition to the many already demonstrated applications in chemical and biological analysis [27], microchemical systems are expected to have numerous advantages for chemical kinetics studies [26] or on-site toxic and hazardous chemical synthesis [28]. In all of the reported examples [25]-[32], microchemical devices and systems are advantageous in large part simply because they are smaller and more compact - a trend for process miniaturization [29].

Moreover, researchers from the field of process engineering have realized that the advantages of microstructured components are not only limited to simple miniaturization, and a number of promising applications involving moderate and, in some cases, even large quantities of matter and energy have begun to emerge in the rapidly growing field of process intensification [29]. In this trend, microfabrication technology is not simply utilized to make devices smaller, but rather to improve the chemical processes-a trend for process intensification [29].

In the last few years it has been demonstrated that microfabrication technology offers a new approach for the fabrication of thin and defect-free Pd-composite membranes [30]-[33]. Such thin films increase the achievable flux as well as the selectivity of the membrane, and may eventually also decrease costs, if the batch fabrication potential of microfabrication technology can be exploited. In this approach, Pd alloy films are first deposited on the dense and smooth surface of microfabricated supports. Due to the surface quality, the films cover the support completely, leading to defect-free membranes later. Next, the supports are partially etched from the backside to create pathways for the gases to the Pd surface. The microfabricated supports allow the deposition of very thin films and can be made in forms that have a low mass transfer resistance. For example, Franz et al. [30] developed a microfabricated Pd membrane chip with high flux $\left(1.6 \mathrm{~mol} \mathrm{H}_{2} / \mathrm{m}^{2} \cdot \mathrm{s}\right)$ and high selectivity (1800 for $\mathrm{H}_{2}$ over $\mathrm{N}_{2}$ ), suitable for hydrogen purification in the laboratory, where normally only a small amount of high quality hydrogen is required.

Most of the microfabricated Pd membranes reported up to now only have a limited size [30]-[32], therefore they are unsuitable for the separation of high volumes of hydrogen. The study presented in this paper focuses on the fabrication of a robust wafer-scale separation module, which may be numbered up easily to create a system with high hydrogen throughput, suitable for industrial applications. In our work, submicron thick Pd-Ag membranes are made on a supporting microsieve, utilizing microfabrication techniques like thin film sputter deposition, $\mathrm{KOH}$ etching of silicon, dry etching of silicon nitride, and anodic wafer bonding. The microfabrication results and the membrane performance in terms of hydrogen separation flux and selectivity will be presented and discussed.

\section{MiCROFABRiCATION OF MEMbRAne Module}

\section{A. Microfabrication of Pd-Ag Membranes on a Supporting Microsieve}

A cross section of the Pd-Ag membrane module is shown in Fig. 1. A Pd-Ag membrane is microfabricated on a supporting microsieve on a $\{110\}$ silicon wafer $(\{110\}-\mathrm{Si})$, then sandwiched between two thick glass wafers to form a membrane module.

The process steps to come to the Pd-Ag membrane are shown in Fig. 2, and are as follows: a 4-inch double-side polished $\{110\}-\mathrm{Si}$ is coated with $0.2 \mu \mathrm{m}$ of wet-thermal silicon dioxide $\left(\mathrm{SiO}_{2}\right)$ and $1 \mu \mathrm{m}$ of low-stress silicon-rich silicon nitride ( $\mathrm{SiN}$ ) by means of low-pressure chemical-vapor deposition (LPCVD) [34]. Parallelogram-shaped structures of 600 by $2600 \mu \mathrm{m}$ [see Fig. 3(a)] are aligned and imprinted on the backside of the wafer by standard photolithography, followed by dry etching of the $\mathrm{SiN}$ in a $\mathrm{CHF}_{3}+\mathrm{O}_{2}$ plasma and wet etching of the oxide layer using a buffered hydrofluoric acid (BHF)(step 2a). A detailed design of the parallelogram-shaped structure that can be etched 


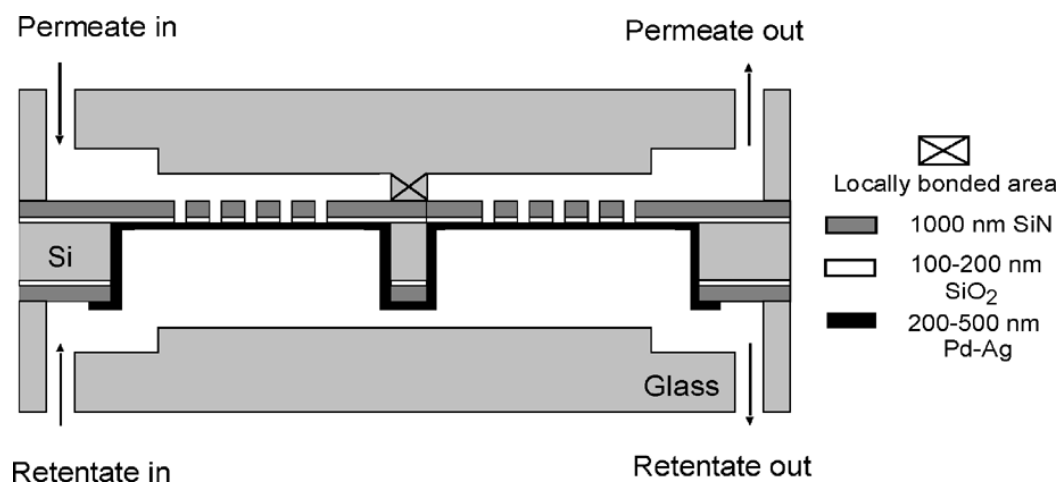

Fig. 1. Cross section of the separation membrane module; only two membrane/microsieve segments are drawn for illustration.

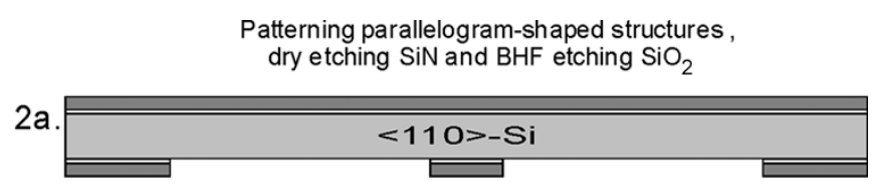

$\mathrm{KOH}$ etching of $\mathrm{Si}$

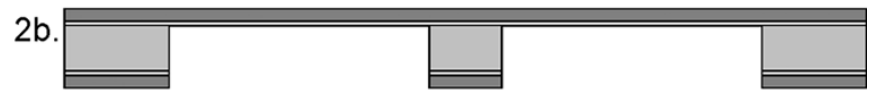

Patterning a microsieve

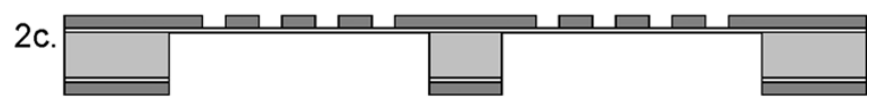

Dual-sputtering Pd-Ag

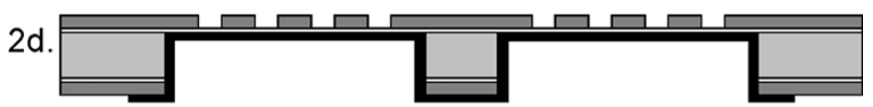

BHF etching $\mathrm{SiO}_{2}$ to release the membrane

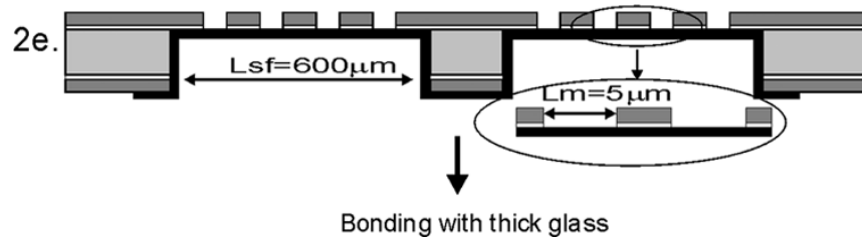

Fig. 2. Fabrication process of the Pd-Ag membrane module.

into $\{110\}-\mathrm{Si}$ in a $\mathrm{KOH}$ solution is depicted in Fig. 3(a) [35], [36].

The wafer is immersed in $25 \% \mathrm{KOH}$ solution at $75^{\circ} \mathrm{C}$ to etch the silicon until the $\mathrm{SiO}_{2}$ layer is reached, thus forming an array of suspended bilayer $\mathrm{SiN} / \mathrm{SiO}_{2}$ membranes (step 2b). Afterwards, standard lithography and dry etching of SiN are carried out on the front-side of the wafer to pattern a microsieve with circular openings of $5 \mu \mathrm{m}$ [37] on the suspended $\mathrm{SiN} / \mathrm{SiO}_{2}$ membranes. The SiN dry etching process is controlled to stop on the $\mathrm{SiO}_{2}$ layer, thus creating a $\mathrm{SiN}$ microsieve on top of the $\mathrm{SiO}_{2}$ membrane (step 2c). From hereon, we define a group of circular sieves patterned in one suspended $\mathrm{SiN} / \mathrm{SiO}_{2}$ membrane as a "microsieve segment." Although in our work the $\mathrm{SiN} / \mathrm{SiO}_{2}$ supporting structures are created by using a $\mathrm{KOH}$ etching of a $\{110\}$-Si substrate, such supports may also be created by using $\mathrm{KOH}$ etching of a $\{100\}$-Si substrate, as described in the work of Franz et al. [30]. The advantages of using $\{110\}-\mathrm{Si}$ are that due to the fact that the slow etching $\{111\}$ planes that remain after $\mathrm{KOH}$ etching are perpendicular to the surface of $\{110\}-\mathrm{Si}$ wafers, fabrication of long but narrow supports with a high density is possible. Additionally, this type of anisotropy makes the support width, the main parameter that determines support strength [37], independent on wafer thickness.

After $\mathrm{KOH}$ etching, alloy films of Pd-Ag are deposited on the flat side of the $\mathrm{SiO}_{2}$ membrane by simultaneous sputtering from two pure targets, one of Pd and one of Ag (both of 99.999\%; Materials Target Co.), on $20 \mathrm{~nm}$ of sputtered titanium (Ti) that acts as an adhesion layer. The detailed dual-sputtering procedure and the properties of the-as deposited $\mathrm{Pd}-\mathrm{Ag}$ films were reported previously [33]. In the current work, we deposited Pd-Ag films with a thickness between 200 to $500 \mathrm{~nm}$ and a $\mathrm{Ag}$ content of $23 \mathrm{wt} \%$.

First the $\mathrm{SiO}_{2}$ and then the $\mathrm{Ti}$ are removed by etching with a BHF solution through the opening of the sieves to reveal the back surface of the Pd-Ag film. A cross section of the resulting $\mathrm{Pd}-\mathrm{Ag}$ membrane on the microsieve segment is depicted in Fig. 3(b). Fig. 4 is a Scanning Electron Microscope (SEM) image of a $500-\mathrm{nm}$-thick Pd-Ag membrane on the SiN microsieve. It can be seen that the $\mathrm{Pd}-\mathrm{Ag}$ membrane is uniform in thickness, has a smooth surface, and seems to be defect-free.

As mentioned above, depositing the film on the planar surface of the sacrificial $\mathrm{SiO}_{2}$ layer and release it later seems to be the key to obtain submicron-thick films of good quality. Additional advantages like low gas transfer resistance for hydrogen will be discussed in Section III-B.

Finally, the silicon wafer is bonded between two thick glass wafers (Borofloat; Schott Co.) by a four-electrode anodic bonding technique [33]. Before the bonding procedure, powder blasting is used to create a flow channel of $200 \mu \mathrm{m}$ depth and a buffer zone of $1000 \mu \mathrm{m}$ in the glass wafers [33]. The bonding process results in a tight seal between each glass wafer and the silicon wafer and creates a membrane module, which is robust enough for practical use. For example, in this form it was integrated in a stainless steel membrane holder [33] to have connections to a gas manifold and a measurement setup.

\section{B. Membrane Area and Porosity}

The width of a microsieve segment is equal to that of the designed parallelogram-shaped structure of $600 \mu \mathrm{m}$ (Fig. 3), while its length Lsg is given by [35]:

$$
\mathrm{Lsg}=\mathrm{Lp}-2 \sqrt{3} \mathrm{D}+\frac{3 \sqrt{2}}{4} \mathrm{Lsf}
$$



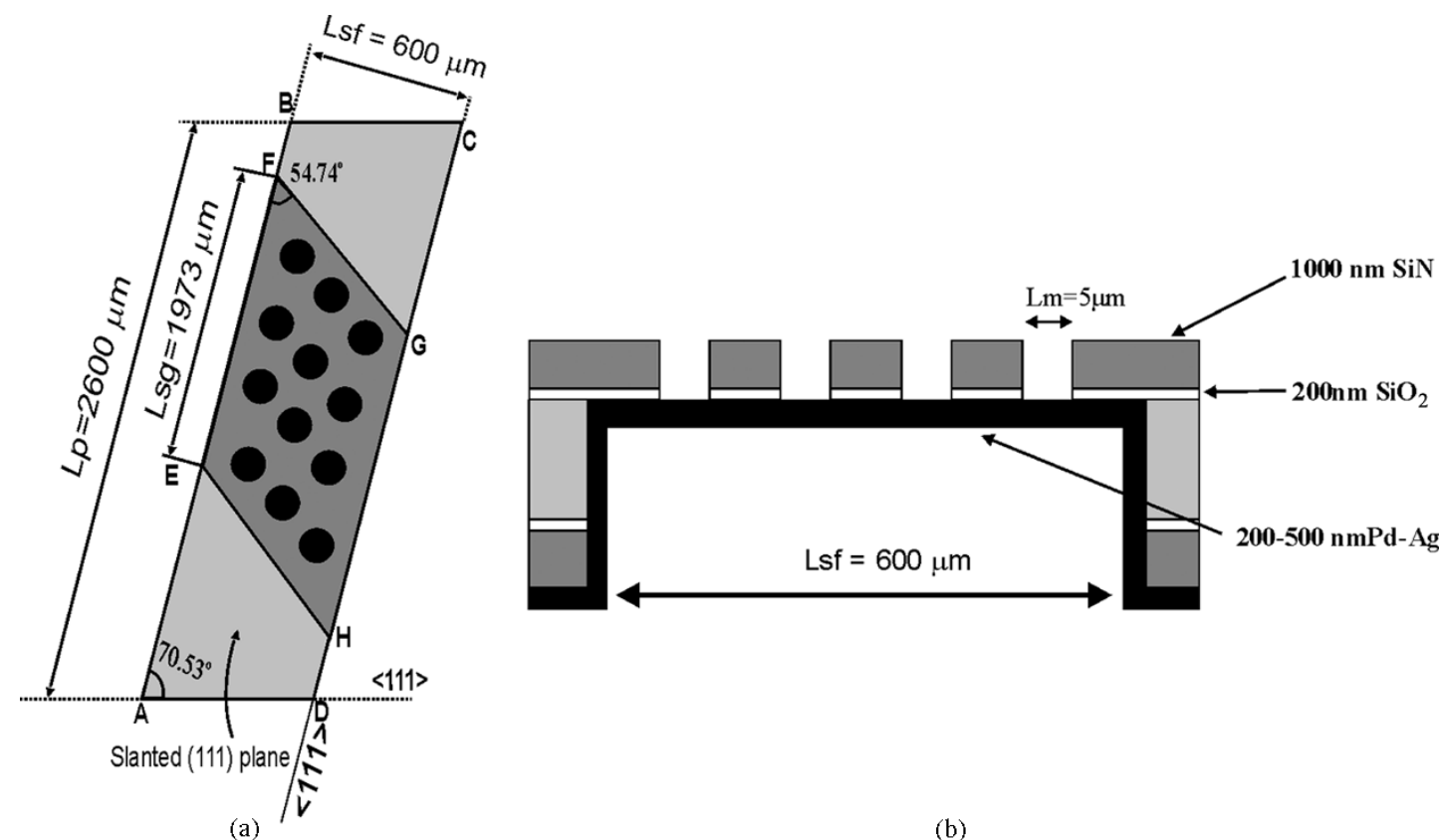

(a)

(b)

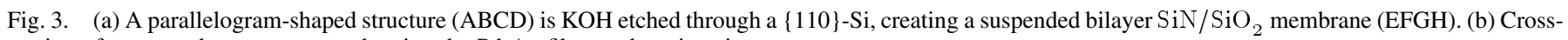
section of one membrane segment, showing the Pd-Ag film on the microsieves.

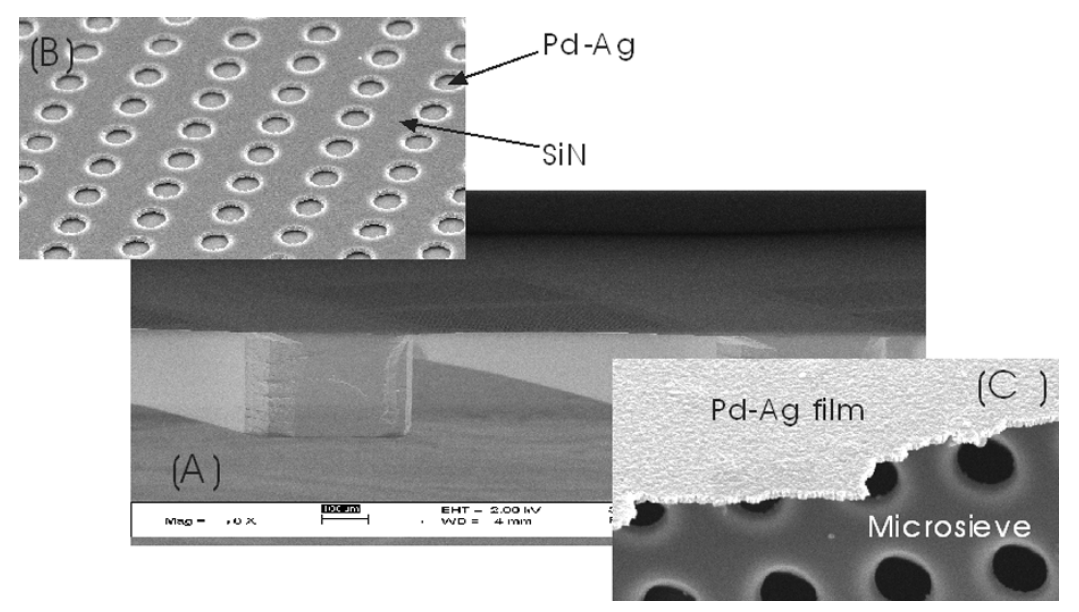

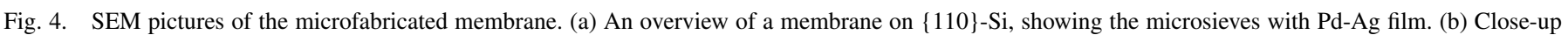

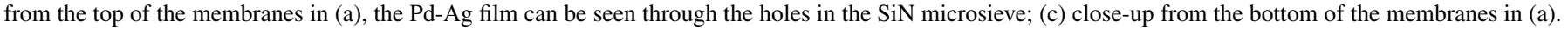

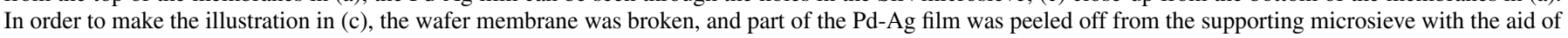
adhesive tape.

with Lp the length and Lsf the width of the parallelogramshaped structure, and D the thickness of Si wafer. Applying (1) with $\mathrm{Lp}=2600 \mu \mathrm{m}, \mathrm{D}=380 \mu \mathrm{m}$ and Lsf $=600 \mu \mathrm{m}$, gives a length Lsg of $1920 \mu \mathrm{m}$. As a result, etching one parallelogram-shaped structure of $2600 \mu \mathrm{m}$ by $600 \mu \mathrm{m}$ through a $\{110\}$-Si wafer creates a suspended area of ca. $1920 \mu \mathrm{m}$ by $600 \mu \mathrm{m}$. In the current design, the porosity of the supporting microsieve is about 20\% [see Fig. 3(b)], which corresponds to an effective area of ca. $0.23 \mathrm{~mm}^{2}$ for hydrogen separation. Several hundreds of such microsieve segments are patterned on a 4-inch silicon wafer to create a large total membrane area for hydrogen separation. Although the porosity of the membrane in the microsieve is about $20 \%$, due to recesses of $300 \mu \mathrm{m}$ between the parallelogram-shaped structures, the real porosity of the membrane, defined here as the relative area of the Pd-Ag film that is available for hydrogen permeation to the area of the silicon wafer, is reduced to about $10 \%$. It is possible though to design a supporting microsieve with slits instead of circular holes [36], which may increase the microsieve porosity to $40 \%-50 \%$, giving a membrane with real porosity of ca. $20 \%$.

\section{Mechanical Strength of the Membrane}

The mechanical strength of the membrane depends on that of the free Pd-Ag film and on the SiN microsieve itself. These parameters are discussed in the next paragraph.

According to van Rijn et al., if a pressure difference $q$ is applied across a thin membrane, it will induce a tensile stress $\sigma_{\text {stretch }}$ and a bending stress $\sigma_{\text {bend }}$ in the membrane [37]. If internal stresses in the materials are neglected, the total tensile 
stress $\sigma_{\text {total }}$ in the membrane is the sum of the average tensile stress and the bending stress

$$
\sigma_{\text {total }}=\sigma_{\text {stretch }}+\sigma_{\text {bend }}=0.29 \sqrt[3]{\frac{q^{2} l^{2} E}{h^{2}}}+1.15 \sqrt[3]{\frac{q^{2} l^{2} E}{h^{2}}}
$$

where $h$ is the thickness of the membrane, $l$ the length of the shortest side of the membrane, and $E$ the Young's modulus of the membrane material. Equation (2) is based on the fact that the largest bending stress occurs at the edge of the membrane.

For brittle materials like ceramics or glasses, which do not possess a stress regime above the yield stress $\sigma_{\text {yield }}\left(\sigma_{\text {yield }}=\sigma_{\text {ultimate }}\right)$, the membrane will rupture at the yield stress. The maximum transmembrane pressure $q_{\text {break }}$ for a thin, brittle membrane is calculated by (2) with $\sigma_{\text {total }}=\sigma_{\text {ultimate }}$

$$
q_{\text {break }}=q_{\text {yield }}=0.58 \frac{h \sigma_{\text {yield }}^{\frac{3}{2}}}{l E^{\frac{1}{2}}}
$$

For a perforated membrane, this has to be multiplied by a strength reduction factor $K(K<1)$ due to the perforation [37]

$$
q_{\text {break }}=q_{\text {yield }}=0.58 K \frac{h \sigma_{\text {ultimate }}^{\frac{3}{2}}}{l E^{\frac{1}{2}}} .
$$

In the above approximate equations [see (2)-(4)] internal stresses in the materials are not taken into account. It is well known that stochiometric silicon nitride membranes fracture at relatively low pressure due to high intrinsic tensile stress of the order of $1 \mathrm{Gpa}$ [38]. The intrinsic tensile stress $\sigma_{\mathrm{o}}$ in a silicon-rich silicon nitride membrane with thickness $1 \mu \mathrm{m}$ is much smaller, ranging from $0.8 * 10^{8}$ to $1.6 * 10^{8} \mathrm{~Pa}$ [39]. The maximum tensile stress $\sigma_{\text {yield }}$ for silicon-rich silicon nitride material fabricated in our laboratory is about $4 * 10^{9} \mathrm{~Pa}$ before rupture occurs [34], [37]-[39]. Setting (4) for the SiN microsieve resting on the silicon support with $\sigma_{\text {yield }}=\sigma_{\text {ultimate }}=4 * 10^{9} \mathrm{~Pa}, \mathrm{E}=2.9 * 10^{11} \mathrm{~Pa}[34]$, [37]-[39], l $=\mathrm{Lsf}=600 \mu \mathrm{m}, \mathrm{h}=1 \mu \mathrm{m}$, and $K=0.7$, we find a $q_{\text {break }}$ of ca. 3.2 bars for the present microsieve.

For ductile materials like most metals, polymers and alloys, there is a linear relation between the strain and the applied stress up to $\sigma_{\text {yield }}$. The membranes will not break when $\sigma_{\text {yield }}$ is reached, but deform. The value of $q_{\text {yield }}$ calculated by (3) gives a lower limit for the maximum pressure $q_{\mathrm{b} r e a k}$-ductile. Experimentally, van Rijn et al. found out that $q_{\text {break-ductile }}$ is approximately one order of magnitude higher than the lower limit $q_{\text {yield }}$ estimated by (3).

From our previous work, we know that the as-deposited Pd-Ag films behave like a ductile material [33], and the used data of $\sigma_{\text {yield }}=80 * 10^{6} \mathrm{~Pa}, \mathrm{E}=150 * 10^{9} \mathrm{~Pa}$ for the deposited Pd-Ag films worked rather appropriately [33]. Thus, setting (3) with $\sigma_{\text {yield }}=80 * 10^{6} \mathrm{~Pa}, E=150 * 10^{9} \mathrm{~Pa}$ [33], $l=\mathrm{Lm}=5 \mu \mathrm{m}, h=0.5 \mu \mathrm{m}$, we find a lower limit of about 1 bar for the Pd-Ag film resting on the microsieve. Since it was argued above that the breaking stress for a ductile material may be up to 10 times higher than the yield stress, we anticipated that the Pd-Ag film will be able to withstand a pressure difference of 5-10 bars.

The rupture strength of the membrane at room temperature was measured in the set up that was described in [37]. Tests showed that the $500 \mathrm{~nm}$ thick $\mathrm{Pd}-\mathrm{Ag} /$ microsieve membrane broken at a pressure difference of $4 \pm 0.5$ bars. However, contrary to our expectations, in most of the mechanical tests the Pd-Ag film broke first, and not the microsieve. This may be due to the fact that the mechanical properties of thin films may be different for different deposition methods and conditions, leading to the use of inappropriate data $\left(\sigma_{\text {yield }}\right.$ and $E$ ) for the mechanical strength estimation of Pd-Ag films.

Although the rupture strength of the membrane has not been measured yet at the high temperatures at which membrane separation should be performed, the room temperature tests indicate that the microfabricated membrane are likely to be stable under the desired pressure gradient.

\section{Hydrogen SEPARATION PERformance}

\section{A. Test Setup}

The permeability of the membrane was determined for $\mathrm{H}_{2}$ and helium $(\mathrm{He})$ with the experimental setup shown in Fig. 5. Nitrogen $\left(\mathrm{N}_{2}\right)$ was used as a sweep gas at the permeate side. All feed flow rates were measured and controlled with mass flow controllers (Bronkhorst High-Tec, EL-FLOW), the permeate pressure was measured and controlled with an absolute pressure controller (Bronkhorst High-Tec, EL-PRESS). The trans-membrane pressure, the pressure drop over the permeate side, and the pressure drop over the retentate side were also measured (Hottinger Baldwin Messtechnik, PD1). The $\mathrm{H}_{2}$ and $\mathrm{He}$ concentrations in the permeate gas were measured by a Gas Chromatograph (GC) equipped with a Thermal Conductivity Detector (TCD) and a 5- $\AA$-molecular sieve column. Argon (Ar) was used as the carrier gas, which gives the TCD a high sensitivity to $\mathrm{H}_{2}$ and $\mathrm{He}$, and a poor sensitivity to $\mathrm{N}_{2}$. The purity of all gases used was $5 \mathrm{~N}$.

The membrane module was placed in a stainless steel holder [33], which was installed in a temperature-controlled oven to ensure isothermal operation. The $\mathrm{H}_{2} / \mathrm{He}$ feed and the sweep gas were preheated in spirals placed in the same oven. The feed flow was varied between 300 and $1000 \mathrm{ml} / \mathrm{min}$ and the $\mathrm{H}_{2}$ molar fraction was varied from 0.1 to $0.9 \mathrm{~mol} / \mathrm{mol}$, while the sweep gas flow was kept constant at $300 \mathrm{ml} / \mathrm{min}$. The experimental set-up was controlled by a PLC. A PC with Labview handled the data-acquisition at $100 \mathrm{~Hz}$. The setup was running fully automatically for $24 \mathrm{~h} / \mathrm{day}$, and could handle 100 recipes without user intervention. For each recipe, 4 samples per hour were taken of the permeate and analyzed by GC.

\section{B. Hydrogen Separation of the Membrane}

1) Separation Flux: The hydrogen flow rate through the $500 \mathrm{~nm}$ Pd-Ag membrane versus the duration of the experiment is given in Fig. 6. The flux is defined as the molecular hydrogen flow through the membrane divided by the free $\mathrm{Pd}-\mathrm{Ag}$ area (mole $\mathrm{H}_{2} / \mathrm{m}^{2} . \mathrm{s}$ ). At a membrane temperature of $450{ }^{\circ} \mathrm{C}$ and a hydrogen partial pressure of $83 \mathrm{kPa}$ at the retentate side, a hydrogen flux of ca. $4 \mathrm{~mol} \mathrm{H}_{2} / \mathrm{m}^{2}$.s was measured. This flux 


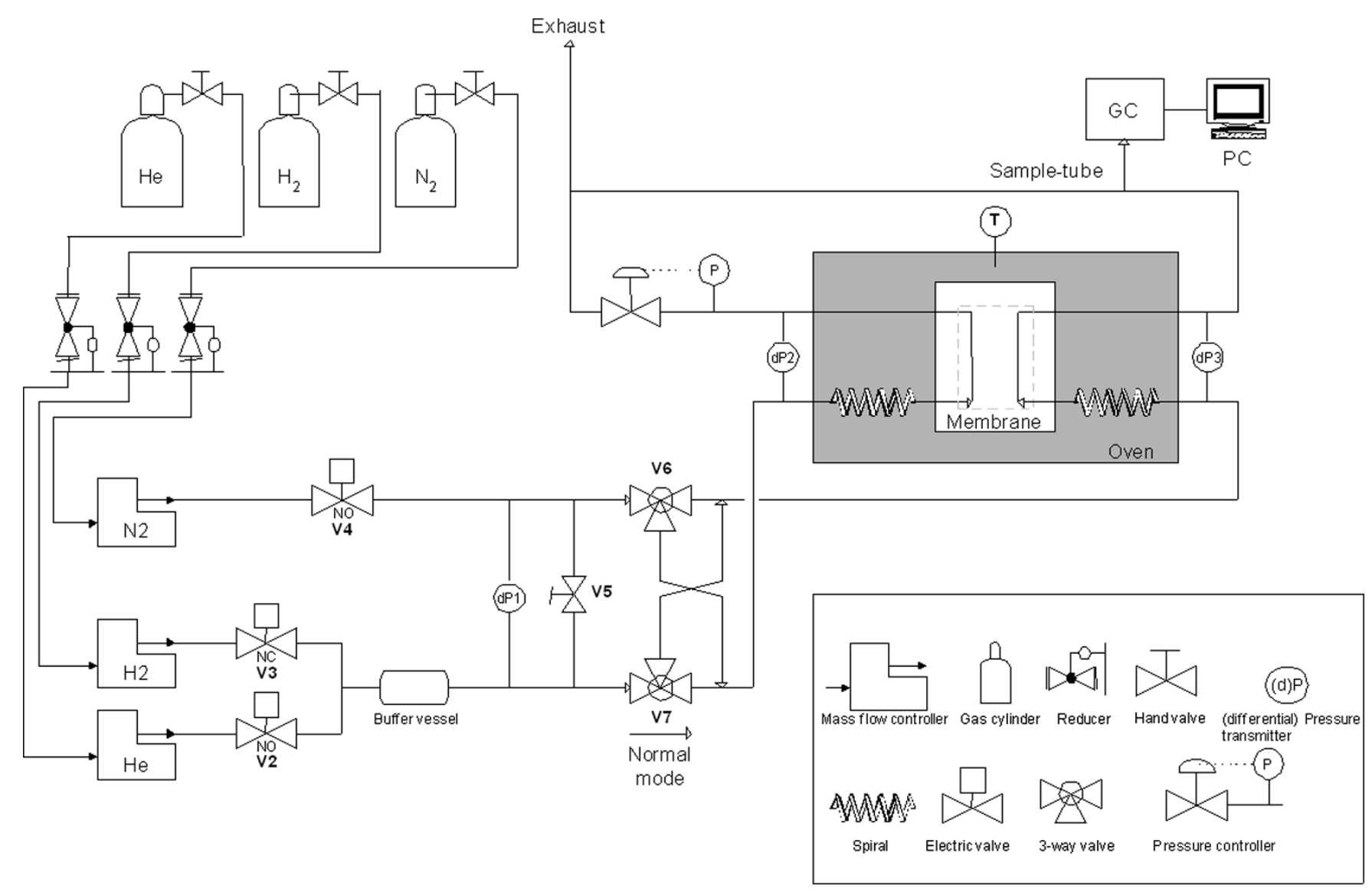

Fig. 5. Schematic drawing of the hydrogen separation setup.

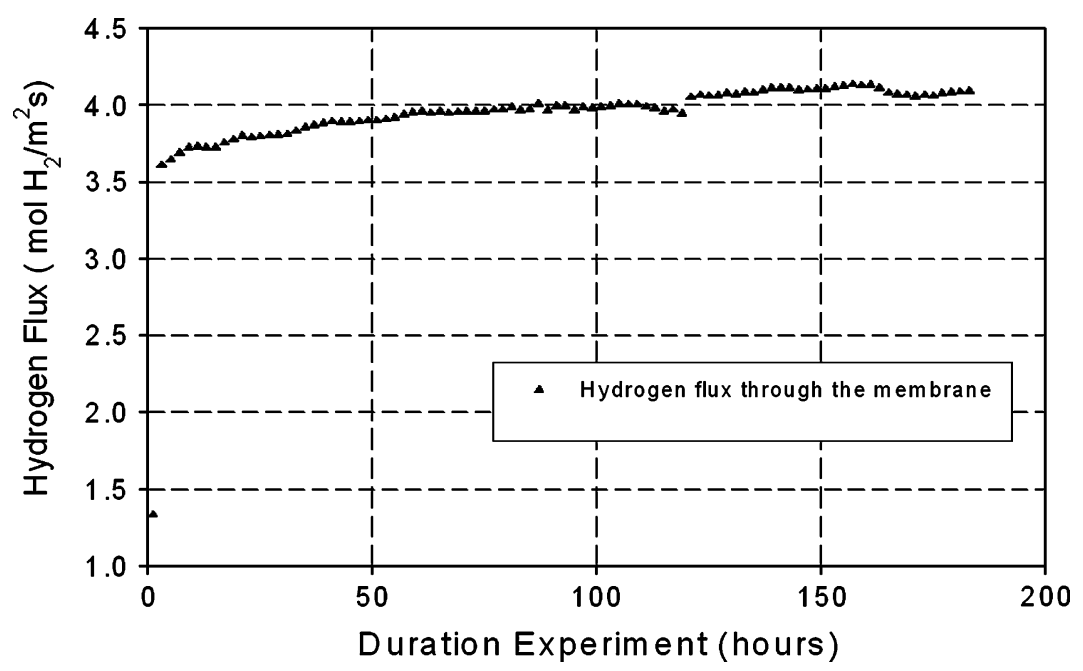

Fig. 6. Hydrogen flow rate through the membrane as a function of time at a temperature of $450{ }^{\circ} \mathrm{C}$ and a hydrogen pressure of $83 \mathrm{kPa}$ in the retentate. After measuring for $120 \mathrm{~h}$, the retentate flow rate was increased from 600 to $900 \mathrm{ml} / \mathrm{min}$, corresponding with an increase in the hydrogen separation flux from ca. $4-4.2 \mathrm{~mol} \mathrm{H}_{2} / \mathrm{m}^{2} \cdot \mathrm{s}$.

is one to two orders of magnitude higher than that through conventional membranes, and compares very well to that of other microfabricated membranes (see Table I).

It has been reported that significant discrepancies exist in literature on hydrogen permeation through thin $\mathrm{Pd} / \mathrm{Ag}$ membranes prepared by different methods [17]. These discrepancies could not be explained by the differences in membrane thickness, composition, or preparation methods [17], [40]. We attribute the high fluxes obtained for the present membrane to the fact that in our work a uniformly thin $(500 \mathrm{~nm})$ and Pd-Ag alloy membrane with high compositional control was achieved [33], which, and this is considered to be crucial, to the fact that the alloy membranes are manufactured on a partially open structure, leaving only the Pd-Ag membrane as a resistance for mass transfer. The latter will be discussed in more detail below.

It is known that the mass transfer resistance associated with viscous flow (Hagen-Poiseuille type) or diffusion through a porous support is very significant in a composite membrane 
TABLE I

Estimated Costs to MaKe a 500-nm Pd77-Ag23 wt\% MEMBrane on a 6-inch $\{110\}$-Si WAFER

\begin{tabular}{l|c}
\hline Items & Cost (\$) \\
\hline 6-in., DSP, $\{110\} \mathrm{Si}$ wafer $+0.3 \mu \mathrm{m} \mathrm{SiO}_{2}+1 \mu \mathrm{m} \mathrm{SiN}$ & 100 \\
\hline 6-in., glass substrates, $5 \mathrm{~mm}$ thick & $60(30 \times 2)$ \\
\hline Pd and Ag materials & 10 \\
\hline \multicolumn{2}{c|}{ Clean-room cost* } \\
\hline \multicolumn{2}{c}{ Total cost } \\
\hline (lithography, dry etching, KOH etching, sputtering, bonding ) \\
\hline We estimated the clean-room cost as being equal to the costs of the main materials, \\
based on our experience with industrial production of microsieves for beer filtration [36].
\end{tabular}

[17]. The viscous flow with flux $J$ through a porous support may be calculated as [41]:

$$
J=\frac{\varepsilon}{8 \eta \tau} \frac{r^{2}}{R T L} P m * \Delta P
$$

where the driving force is $\Delta \mathrm{p}=\mathrm{P}_{1}-\mathrm{P}_{2}, \varepsilon$ is the porosity, $\tau$ is the tortuosity, $r$ is the average pore diameter, $L$ is the thickness of the porous medium, and $\eta$ is the viscosity of the gases, the mean pressure $\mathrm{Pm}=0.5\left(\mathrm{P}_{1}+\mathrm{P}_{2}\right)$ with $\mathrm{P}_{1}$ and $\mathrm{P}_{2}$ the pressure at the inlet and outlet of the porous support, respectively. Applying (5), Ward and Dao estimated that to have a viscous $\mathrm{H}_{2}$ flow of $10^{-3} \mathrm{~mol} / \mathrm{cm}^{-2}$.s at $300{ }^{\circ} \mathrm{C}$ through a $1-\mathrm{mm}$ thick porous support with a porosity of $50 \%$, a tortuosity of 3 , and average pore diameter of $5 \mu \mathrm{m}$ would require a $\mathrm{H}_{2}$ pressure drop of approximately 0.4 bar over the support, assuming $\mathrm{P}_{2}=0$ and no other mass transfer resistance [17]. Apparently, the presence of the porous supports in the conventional membrane construction significantly reduces the driving force across the $\mathrm{Pd}$ layer, thus restricting the separation flux. For our membrane construction (Figs. 1 and 3) and other microfabricated membranes [30]-[33], the same $\mathrm{H}_{2}$ flow would have to travel through a thinner support $(0.4 \mathrm{~mm}$ thick in our case) with much larger pores $(600 \mu \mathrm{m}$ in the present membrane design, neglecting the flow resistance of the holes in the $\mathrm{SiN}$, which are only $5 \mu \mathrm{m}$ wide and $1.2 \mu \mathrm{m}$ deep [see Fig. 3(b)] to access the Pd-Ag surface, thus requiring a much smaller pressure drop. Computer simulations (using flow solver CFX4.2) gave a pressure drop from the inlet to the membrane surface of less than $5 \%$ of the total pressure difference, for a membrane with micromachined support structures of $28 \mu \mathrm{m}$ [42]. As a result, our membrane should allow a higher separation flux.

Fig. 6 shows that the flux is stable within ca. $10 \%$, with a slow increase from ca. $3.6 \mathrm{~mol} \mathrm{H} / \mathrm{m}^{2} \cdot \mathrm{s}$ to $4 \mathrm{~mol} \mathrm{H} / \mathrm{m}^{2}$.s over the first 50 hours before becoming stable within $1 \%$. The increase of the flux in the first measuring period may be explained by an increase in Pd grain size, as was proposed by Lin [40], although in our case the rise in the flux is much less than that observed by Lin. In the measurement, the retentate flow rate was increased about $50 \%$ from 600 to $900 \mathrm{ml} \cdot \mathrm{min}^{-1}$ after $120 \mathrm{~h}$. This led to only a very small increase in the separation flux, suggesting that the separation flux of about $4 \mathrm{~mol} \mathrm{H} / \mathrm{m}^{2} \cdot \mathrm{s}$ is the maximum attainable value under these conditions.
One membrane module was investigated for a relatively long period of ca. 1000 hours, during which the membrane experienced a change in gas type and concentration, as well as temperature cycling between $20-450^{\circ} \mathrm{C}$. The measured results showed no significant reduction in flux or selectivity, suggesting excellent membrane stability. In the case of direct deposition of metal films on porous supports, strong interactions between metal and support may occur, especially when the top layer of the support has very small pores, which was found to lead to instable performance in terms of both separation flux and selectivity [12], [16]. In the microfabricated membrane construction (Fig. 2(e) and Fig. 4), the Pd-Ag film, which is used to separate the hydrogen is free-standing. In the typical range of temperatures in which hydrogen separation is performed (up to $500^{\circ} \mathrm{C}$ ), hardly any diffusion is expected of the metals ( $\mathrm{Pd}, \mathrm{Ag}$, and $\mathrm{Ti}$ ) into the support, which is composed of $\mathrm{SiN}$ on $\mathrm{SiO}_{2}$, materials well known as good diffusion barriers in IC technology.

As hydrogen transport through Pd films occurs via a solution/diffusion mechanism, it is of interest to know which step is rate-limiting in the separation process. Hydrogen transport through the metal films is frequently described by the following empirical equation [8], [9], [17]:

$$
J=\frac{Q}{h}\left(P_{\text {retentate }}^{n}-P_{\text {permeate }}^{n}\right)
$$

where $J$ is the flux of hydrogen, $Q$ the permeability, $h$ denotes the thickness of the membrane layer, $P_{\text {retentate }}^{n}$ and $P_{\text {permeate }}^{n}$ stand for the hydrogen partial pressure in the retentate and permeate respectively, $n$ the hydrogen pressure exponent, which is often used as an indicator for the rate-controlling step of the overall permeation through a metal composite membrane. When diffusion through the bulk metal is the rate-limiting step and hydrogen atoms form an ideal solution in the metal (Sievert's law of the hydrogen solubility dependence), $n$ is equal to 0.5 . A value of $n$ greater than 0.5 may result when surface processes influence the permeation rate or when Sievert's law is not obeyed. It is expected that as the membrane thickness decreases to the submicron range, diffusion of hydrogen atoms becomes extremely fast. In that case, the $n$-value will be close to 1 [7]-[9], [13]-[18].

To determine which step limits the $\mathrm{H}_{2}$ transport rate, experiments were carried out with varying $\mathrm{H}_{2}$ concentration in the 


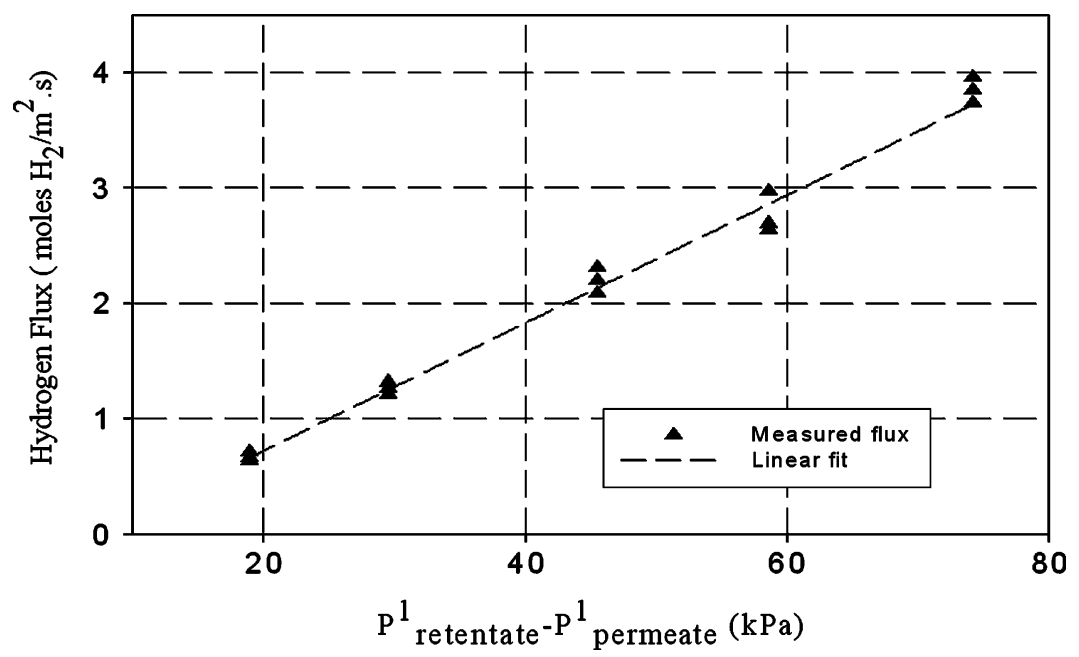

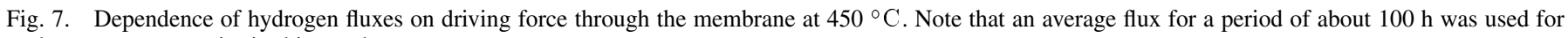
each measurement point in this graph.

feed from 18 to $83 \mathrm{kPa}$ at $450^{\circ} \mathrm{C}$. In Fig. 7 the measured fluxes are plotted against the difference in hydrogen partial pressure in retentate and permeate, which gives a value of $\mathrm{n}$ close to 1 for $500 \mathrm{~nm}$ thin Pd-Ag membrane. This $n$-value indicates that surface processes dominate the separation process, which is consistent with common observations for submicron thick Pd-based membranes [7]-[9], [13]-[18].

The fact that in our experiments hydrogen transport though the Pd-Ag film is governed by surface reactions may be caused by several reasons:

1) the diffusion of hydrogen atoms through the submicron thick Pd-Ag film may be extremely fast, therefore, its influence on the overall hydrogen transport is very small;

2) the membrane surface was possibly polluted during the fabrication process or during measurement;

3) Pd and $\mathrm{Ag}$ from the Pd-Ag film segregate to the two sides of the membrane, adding an extra resistance to the surface processes [43].

To investigate the hypothesis that the membrane was contaminated during processing, several membranes were checked by XPS or Energy dispersive X-ray (EDX) before bonding them between the glass substrates, but there was no indication of contamination on the Pd-Ag film surface. However, we could not check the membrane state after the bonding step due to the coverage by the glass substrates, so it remains unknown whether contamination may arises from the anodic bonding process. Since bonding was carried out in vacuum, such contamination is not expected. It is possible that the membrane became polluted with carbon, introduced from the graphite sealing, a possibility reported by Lin [40]. Other sources of carbon may be from ambient air [44], [45]. For instance, Hughes et al. fabricated Pd-Ag alloy films for MIS gas sensors and found from their sputtered Auger profiling that the surface of the deposited films was always contaminated by at least carbon, which was presumed to originate from the ambient air [44], [45].

Currently, experiments are performed to investigate the influence of $\mathrm{CO}, \mathrm{CO}_{2}$ or steam on membrane performance. We believe that a better understanding of the membrane properties will help us to fabricate membranes with a lower surface resistance, leading to even higher hydrogen separation fluxes.
2) Membrane Selectivity: Possible membrane leaks during the permeation experiment can be detected by measuring the $\mathrm{He}$ concentration at the permeate side. However, no He was found during the experiments. Therefore, in order to calculate a minimum selectivity of $\mathrm{H}_{2}$ over $\mathrm{He}$, the detection limit of the gas chromatograph for $\mathrm{He}$ is used as the maximum He concentration. In this way, a minimal separation factor of 1500 for $\mathrm{H}_{2}$ to He is calculated. This high selectivity indicates that the microfabricated membrane is most likely defect-free. We believe that depositing the Pd-Ag separation layer on a very smooth and clean $\mathrm{SiO}_{2}$ layer and preparing the membrane in a clean room environment were the key parameters to get to this result. This is consistent with other reports, e.g., Vos and Verweij claimed that the use of a clean room reduced the average concentration of particles of $0.5 \mu \mathrm{m}$ from 18 million $\mathrm{m}^{-3}$ in normal laboratory air to less than $100 \mathrm{~m}^{-3}$ in a class 100 clean room, where our membranes are prepared [46]. Without clean-room conditions, the number of defects caused by particles from the air was estimated to be at least five defects with a diameter over $0.5 \mu \mathrm{m}$ per $\mathrm{cm}^{2}$ of membrane surface. This number dropped to far below 1 when clean room conditions were applied.

\section{Membrane Utilization}

Although the thickness of the Pd-Ag membrane has been reduced to submicron thickness, the membrane costs are probably still high in comparison to that of composite membranes [46], because our membrane has to be produced in a clean room environment using special techniques. The estimated costs to make membranes in a 6-inch silicon wafer are summarized in Table II. The main retail costs seem to be clean-room expenses as well as silicon and glass substrates, and not the Pd film as is the case for conventional membranes [47]. However, following the general trends in semiconductor technology, we expect that the total membrane costs will be significantly reduced when membranes can be batch-produced.

Considering the high hydrogen separation flux as well as high selectivity, the present membrane is suited for small-scale purification units that supply high-quality hydrogen for applications like fuel-cells, semiconductor materials processing, or 
TABLE II

Comparison of Permeation Results for Thin Sputtered Pd AND Pd-Alloy Membranes

\begin{tabular}{|c|c|c|c|c|c|c|}
\hline \multirow[t]{2}{*}{ Membrane } & \multirow{2}{*}{$\begin{array}{c}\text { Thickness } \\
(\mu \mathrm{m})\end{array}$} & \multirow{2}{*}{$\begin{array}{l}\text { Temp. } \\
\left({ }^{\circ} \mathrm{C}\right)\end{array}$} & \multirow{2}{*}{$\begin{array}{c}\text { Pressure } \\
\begin{array}{l}\mathrm{P}_{\text {retentate }}\left(\mathrm{H}_{2}\right) \\
\quad(\mathrm{Bar})\end{array}\end{array}$} & \multirow{2}{*}{$\begin{array}{c}\text { Flux } \\
\left(\mathrm{mol} \mathrm{H}_{2} / \mathrm{m}^{2} \cdot \mathrm{s}\right)\end{array}$} & Selectivity & \multirow[t]{2}{*}{ Refs. } \\
\hline & & & & & $\begin{array}{c}\mathrm{H}_{2} / \mathrm{N}_{2} \text { or } \\
\mathrm{H}_{2} / \mathrm{He} \\
\end{array}$ & \\
\hline $\mathrm{Pd} / \mathrm{SS}$ & 11.4 & 550 & & 0.71 & 380 & {$[12]$} \\
\hline $\mathrm{Pd}-\mathrm{Ag} / \gamma-\mathrm{Al}_{2} \mathrm{O}_{3}$ & 0.35 & 250 & 1 & 0.015 & $5.7^{*}$ & [13] \\
\hline $\mathrm{Pd}-\mathrm{Ag} / \gamma-\mathrm{Al}_{2} \mathrm{O}_{3}$ & $0.16-0.52$ & 300 & Not given & 0.01 & Up to $116^{* *}$ & [14] \\
\hline $\begin{array}{c}\mathrm{Pd} \text { and Pd-Ag/ } \\
\gamma-\alpha \mathrm{Al}_{2} \mathrm{O}_{3} \\
\end{array}$ & $0.1-1.5$ & 300 & 1 & $0.01-0.02$ & $30-200$ & [16] \\
\hline $\mathrm{Pd}-\mathrm{Ag} / \alpha-\mathrm{Al}_{2} \mathrm{O}_{3}$ & $0.7-1.1$ & 350 & $2-5$ & 0.05 & $4-80^{*}$ & [18] \\
\hline Pd-Ru-In/SS & 1.5 & 370 & 1 & 0.03 & Infinite & {$[20]$} \\
\hline $\mathrm{Pd}-\mathrm{Cu} / \mathrm{SS}$ & 2 & 450 & 1 & 0.84 & $3000 *$ & {$[22]$} \\
\hline $\begin{array}{c}\text { Microfabricated } \\
\text { Pd }\end{array}$ & 0.2 & 500 & 0.1 & 1.6 & 1800 & [30] \\
\hline $\begin{array}{c}\text { Microfabricated } \\
\text { Pd }\end{array}$ & 0.2 & 100 & 0.5 & 4.5 & Unknown & [31] \\
\hline $\begin{array}{l}\text { Microfabricated } \\
\text { Pd-Ag }\end{array}$ & 1 & 450 & 0.3 & 0.5 & $\begin{array}{l}\text { More than } \\
550\end{array}$ & [33] \\
\hline $\begin{array}{l}\text { Microfabricated } \\
\text { Pd-Ag }\end{array}$ & 0.5 & 450 & 0.83 & $3.6-4.2$ & $\begin{array}{l}\text { More than } \\
1500\end{array}$ & This work \\
\hline
\end{tabular}

\footnotetext{
* Selectivity for $\mathrm{H}_{2} / \mathrm{N}_{2}$

** Only one membrane had an exceptional selectivity of 3845

SS: porous stainless steel
}

laboratory use [1]-[6], [48], [49]. For example, several manufacturers have proposed fuel cell power systems to produce $1 \mathrm{~kW}$ of electricity for residential use [19], [50]. Production of $1 \mathrm{~kW}$ of electricity would require approximately 600 standard litters per hour (SLPH) of high purity hydrogen. This amount of hydrogen can be purified by using a Pd-Ag membrane made on a 6-inch silicon wafer with a feasible membrane porosity of $20 \%$.

The present technology would allow the construction of an extended module, in which larger and possibly thicker glass plates are used to house a number of membrane wafers. This larger module can be operated in a parallel mode, using the principle of "numbering-up" [29] instead of scaling-up to increase hydrogen throughput. The proposed unit may find an application in a on-site hydrogen production, where small, natural gasbased reformers, being developed for distributed fuel cell power system, could potentially be used to generate hydrogen-rich re- formate streams [51]. Purification is an essential step to remove impurities in the reformate that may poison the storage unit or fuel cell [51]. The numbering-up principle has certain advantages over conventional scale-up. Conventional scale-up entails going from laboratory scale to a single large unit through a series of costly laboratory experiments, simulations, and pilot plan testing [52]. While, because of each microfabricated membrane would behave exactly alike, individually and in replicated units, numbering-up would be considerably shorter and less expensive, allowing for faster transfer time to the market. We think that in certain applications these advantages may override the economies of conventional large plants.

The fabricated membrane may be used as a membrane reactor for dehydrogenation reactions to synthesize high value products [53], [54], although the applicability may be limited as hydrogenation reactions are normally carried out at rather high pressures of tens of bars. Nevertheless, the membrane design [see 
(2)-(4)] can be changed to obtain stronger membranes. Furthermore, the present technology can be used to fabricate other kinds of thin but strong and defect-free membranes [55] to set up new applications. For example, by using the $\mathrm{SiN}$ microsieve as a supporting structure, we have made an ultra thin $(10 \mathrm{~nm})$ but strong SiN membrane for a nanosieve [56]. Alternatively, thin and defect-free Ag-based membranes may be fabricated and applied in oxygen separation [57].

\section{CONCLUSION}

Thin but strong Pd-Ag alloy membranes were fabricated with microfabrication technology and tested. Pd-Ag films were sputtered onto a planar support (a $\mathrm{SiO}_{2} / \mathrm{SiN}$ microsieve $)$ and released later, creating defect free, submicron thick Pd-Ag films. The fabrication method also led to a robust membrane module, which is important for practical use. The microfabricated membranes achieved permeation rates of over $4 \mathrm{~mol} \mathrm{H}_{2} / \mathrm{m}^{2} \cdot \mathrm{s}$ and a $\mathrm{H}_{2} / \mathrm{He}$ selectivity of more than 1500 , with a high long-term stability.

The utilization of the reported membranes at different scales were presented and discussed. The present technology seems to be suitable for fabricating small-scale membrane units for hydrogen purification from gas mixtures. Also, the present membrane may be used as membrane reactors for hydrogenation/ dehydrogenation. The present technology may be used to fabricate other kinds of thin but strong and defect-free membranes to set up new applications.

\section{ACKNOWLEDGMENT}

The authors would like to thank the staff of the MESA ${ }^{+}$Research Institute for Nanotechnology, University of Twente, for technical support.

\section{REFERENCES}

[1] R. Ramachandran and R. K. Menon, "An overview of industrial uses of hydrogen," Int. J. Hydrogen Energy, vol. 23, p. 593, 1998.

[2] A Review of the National Hydrogen Vision Meeting, Washington, DC, Nov. 15-16, 2001.

[3] B. H. C. Steele and A. Heinzel, "Materials for fuel-cell technology," Nature, vol. 414, p. 338, 2001.

[4] P. Hoffmann, Tomorrow's Energy: The MIT Press, 2001.

[5] M. S. Dresselhaus and I. L. Thomas, "Alternative energy technology," Nature, vol. 414, p. 332, 2001.

[6] T. N. Veziroglu, "Hydrogen energy system as a permanent solution to global energy-environment problems," Chem. Ind., vol. 53, p. 383, 1999.

[7] R. Hughes, "Composite palladium membranes for catalytic membrane reactors," Membr. Technol., vol. 131, p. 9, 2001.

[8] J. Shu, B. P. A. Grandjean, A. VanNeste, and J. Kaliaguine, "Catalytic palladium-based membrane reactors: review," Can. J. Chem. Eng., vol. 69 , p. $233,1991$.

[9] R. Dittmeyer, V. Hollein, and K. Daub, "Membrane reactors for hydrogenation and dehydrogenation processes based on supported palladium," J. Molec. Cat. A., vol. 173, p. 135, 2001.

[10] V. A. Goltsov, "Hydrogen treatment (processing) of materials: current status and prospects," J. Alloy. Comp., vol. 293-295, p. 844, 1999.

[11] R. Goto, "Purification of hydrogen by selective osmosis with palladium alloy membranes," КаgаKи КоgaKu, vol. 34, p. 381, 1970.

[12] J. P. Collins and J. D. Way, "Preparation and characterization of a composite palladium-ceramic membrane," Ind. Eng. Chem. Res., vol. 32, p. 3006, 1993.

[13] V. Jayaraman and Y. S. Lin, "Synthesis and hydrogen permeation properties of ultra thin palladium-silver alloy membranes," J. Membr. Sci., vol. 104, p. 251, 1995.
[14] B. McCool, G. Xomeritakis, and Y. S. Lin, "Composition control and hydrogen permeation characteristics of sputter deposited palladium-silver membranes," J. Membr. Sci., vol. 161, p. 67, 1999.

[15] K. L. Yeung and A. Varma, "Novel preparation technique for thin metalceramic composite membranes," AIChE J., vol. 41, no. 9, p. 2131, 1995.

[16] G. Xomeritakis and Y. S. Lin, "CVD synthesis and gas permeation properties of thin palladium/alumina membranes," AIChE. J., vol. 44, p. 174 , 1998.

[17] L. T. Ward and T. Dao, "Model of hydrogen permeation behavior in palladium membranes," J. Membr. Sci., vol. 153, p. 211, 1999.

[18] J. O. Brien, R. Hughes, and J. Hisek, "Pd-Ag membranes on porous alumina substrates by unbalanced magnetron sputtering," Surf. Coat. Technol., vol. 142, p. 253, 2001.

[19] F. Roa, J. D. Way, R. L. McCormick, and S. N. Paglieri, "Preparation and characterization of $\mathrm{Pd}-\mathrm{Cu}$ composite membranes for hydrogen separation," J. Chem. Eng., vol. 93, p. 11, 2003.

[20] S. Yan, H. Maeda, K. Kusakabe, and S. Morooka, "Thin palladium membrane formed in support pores by metal-organic chemical vapor deposition method and application to hydrogen separation," Ind. Eng. Chem. Res., vol. 33, p. 616, 1994.

[21] A. J. Burggraaf, "Key points in understanding and development of ceramic membranes," in Proc. ICIM, vol. 3, 1994, p. 1.

[22] S. E. Nam and K. H. Lee, "Hydrogen separation by Pd alloy composite membrane: introduction of diffusion barrier," J. Membr. Sci., vol. 192, p. $177,2001$.

[23] R. Bredesen and H. Klette, "Method of Manufacturing Thin Metal Membrane," US Patent nr. 6086729

[24] K. D. Wise and K. Najafi, "Microfabrication techniques for integrated sensors and microsystems," Science, vol. 254, p. 1335, 1991.

[25] M. U. Kopp, A. J. de Mello, and A. Manz, "Chemical amplification: continuous-flow PCR on a chip," Science, vol. 280, p. 1046, 1998.

[26] K. F. Jensen, "Chemical kinetics: smaller, faster chemistry," Nature, vol. 393, p. 735, 1998.

[27] Proc. Micro Total Analysis System 2000, A. van den Berg, Ed..

[28] Pro. International Conference on Microreaction Technology 5 (IMRET5), M. Matlosz, W. Ehrfeld, and J. P. Baselt, Eds., 2001.

[29] M. Matlzosz, S. Rode, and J. M. Commenge, "Microstructures for smart reactors: precision performance in industrial production," in Proc. International Conference on Microreaction Technology 5 (IMRET5), 2001, p. 13.

[30] A. J. Franz, K. F. Jensen, and M. A. Schmidt, "Palladium based membranes for hydrogen separation and hydrogenation/dehydrogenation," in Proc. IEEE. MEMS 99, 1999, p. 382.

[31] S. V. Karnik, M. K. Hatalis, and M. V. Kothare, "Toward a palladium micro-membrane for the water gas shift reaction: microfabrication approach and hydrogen purification results," J. Microelectromech. Syst., vol. 12 , p. 93, 2003.

[32] A. Zheng, F. Jones, J. Fang, and T. Cui, "Dehydrogenation of cyclohexane to benzene in a membrane microreactor," in Proc. of International Conference on Microreaction Technology, vol. 4, 2000, p. 284.

[33] H. D. Tong, J. W. Berenschot, M. J. De Boer, J. G. E. Gardeniers, H. Wensink, H. V. Jansen, W. Nijdam, M. Elwenspoek, F. C. Gielens, and C. J. M. Rijn, "Microfabrication of palladium-silver alloy membranes for hydrogen separation," J. Microelectromech. Syst., vol. 12, p. 622, 2003.

[34] J. G. E. Gardeniers, H. A. C. Tilmans, and C. C. G. Visser, "LPCVD silicon-rich silicon nitride films for applications in micromechanics, studied with statistical experimental design," J. Vac. Sci. Technol. A, vol. 14, p. 2879, 1996.

[35] D. L. Kendall, "Vertical etching of silicon at very high aspect ratios," Rev. Sci. Instr., vol. 9, p. 373, 1979.

[36] C. J. M. van Rijn, W. Nijdam, L. A. V. G. Stappen, O. J. A. Raspe, L. Broens, and V. S. Hoof, "Innovation in yeast cell filtration: cost saving with high flux membranes," in Proc. EBC Congress, Maastricht, 1997, p. 501.

[37] C. J. M. van Rijn, M. van der Wekken, W. Nijdam, and M. Elwenspoek, "Deflection and maximum load of microfiltration membrane sieves made with silicon micromachining," J. Microelectromech. Syst., vol. 6, p. 48, 1997.

[38] M. Heschel and S. Bouwstra, "Robust, compliant silicon nitride membranes," in Proc. MME'95, 1995, p. 84.

[39] V. L. Spriering, S. Bouwstra, M. Elwenspoek, and J. F. Burger, "Membranes fabricated with a deep single corrugation for package stress reduction and residual stress relief," J. Micromech. Microeng., vol. 3, p. 243, 1993.

[40] Y. S. Lin, "Microporous and dense inorganic membrane: Current status and prospective," Sep. Pur. Technol., vol. 25, p. 39, 2001. 
[41] A. J. Burggraaf and L. Cot, Eds., Fundamentals of Inorganic Membrane Science and Technology. Amsterdam: Elsevier, 1996.

[42] E. J. Harbers and F. C. Gielens, "Optimization of Mass Transfer Toward and From Hydrogen Selective Palladium Membranes," University of Eindhoven, Internal report, 2001.

[43] J. Shu, B. E. W. Bongondo, B. P. A. Grandjean, and S. Kaliaguine, "Surface segregation of Pd-Ag membrane upon hydrogen permeation," Surf. Sci., vol. 291, p. 129, 1993.

[44] R. C. Hughes, W. K. Schubert, T. E. Zipperian, J. L. Rodriguez, and T. A. Plut, "Thin films of Pd/Ni alloys for detection of high hydrogen concentrations," J. Appl. Phys., vol. 62, p. 1074, 1987.

[45] R. C. Hughes, P. A. Taylor, A. J. Ricco, and R. R. Rye, "Kinetics of hydrogen adsorption and absorption: catalytic gate MIS gas sensors on silicon," J. Electrochem. Soc., vol. 136, p. 2653, 1989.

[46] R. M. Vos and H. Verweij, "High-selectivity, high-flux silica membranes for gas separation," Science, vol. 279, p. 1710, 1998.

[47] A. Criscuoli, A. Basile, E. Drioli, and O. Loiacono, "An economic feasibility study for water gas shift membrane reactor," J. Membr. Sci., vol. 181, p. 21,2001

[48] V. A. Goltsov, "Hydrogen treatment (processing) of materials: current status and prospects," J. Alloy. Comp., vol. 293-295, p. 844, 1999.

[49] V. M. Gryaznov, "Hydrogen permeable palladium membrane catalysts. An aid to the efficient production of ultra pure chemical and pharmaceuticals," Platinum Metal. Rev., vol. 30, p. 68, 1986.

[50] A Fuel Cell Primer: The Promise and the Pitfalls, T. Koppel and J. Reynolds. (2000). http://www.fuelcellstore.com [Online]

[51] S. Lasher, M. Stratonova, and J. Thijssen, "Hydrogen technical analysis," in Proc. US Department of Energy (DOE): Hydrogen Program Rev., Washington, DC, 2001.

[52] R. W. Baker, "Future directions of membrane gas separation technology," Ind. Eng. Chem. Res., vol. 41, p. 1393, 2002.

[53] S. I. Niwa, M. Eswaramoorthy, J. Nair, A. Raj, N. Itoh, H. Shoji, T. Namba, and F. Mizukami, "A one-step conversion of benzene to phenol with a palladium membrane," Science, vol. 295, p. 105, 2002.

[54] Y. She, J. Han, and Y. H. Ma, "Palladium membrane reactor for the dehydrogenation of ethylbenzene to styrene," Cat. Today, vol. 67, p. 43, 2001

[55] C. J. M. van Rijn, Nano and Micro Engineered Membrane Technology: Elsevier Science, 2004

[56] H. D. Tong, H. V. Jansen, V. J. Gadgil, C. G. Bostan, E. Berenschot, C. J. M. van Rijn, and M. Elwenspoek, "Silicon nitride nanosieve membrane," Nanolett., vol. 4, p. 286, 2004

[57] R. E. Coles, "The permeability of silver to oxygen," Brit. J. Appl. Phys., vol. 14, p. 342, 1963.

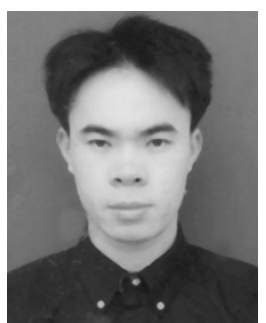

Hien Duy Tong received the M.Sc. degree from the International Training Institute for Materials Science (ITIMS), Ha Noi University of University of Technology, Ha Noi, Viet Nam in 1995. His thesis dealt with a fabrication of pressure sensors by MEMS. After graduation he worked as a research scientist at ITIMS. Since April 2000 to June 2004, he worked towards and received the Ph.D. degree doing research in the Transducers Science and Technology Group at MESA ${ }^{+}$Research Institute for Nanotechnology, University of Twente, The Netherlands. Currently, he is working as postdoctoral researcher in the same research group.

His main research areas are new technologies for microfabricated and nanofabricated-based membranes for molecule and liquid separations.

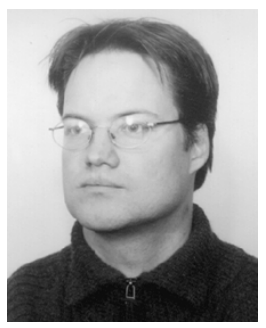

F. C. (Frank) Gielens was born on July 16, 1973 in Zaandam, The Netherlands. He received the M.Sc. degree in chemical engineering from the University of Amsterdam in 1996

From 1997 to 1999 , he followed a Post-Master Design course at the Technical University of Eindhoven and in 1999 he started to work towards the Ph.D. degree in the Process Development group at the Technical University of Eindhoven. His main research area is the characterization and application of hydrogen selective membranes, with emphasis on Pd alloy membranes fabricated with microsystem technology.

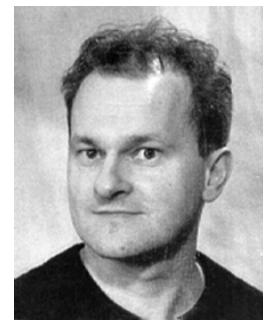

J. G. E. ("Han") Gardeniers received the B.Sc., M.Sc., and the Ph.D. degrees in 1982, 1985, and 1990, respectively

$\mathrm{He}$ joined the Department of Electrical Engineering at the University of Twente, The Netherlands, as an Assistant Professor in 1990. From 2001 to 2003, he was employed as Project Leader MOEMS at Kymata Netherlands B.V./Alcatel Optronics Netherlands B.V. and as Research Manager at Micronit Microfluidics B.V., where he was responsible for R\&D related to miniaturized chemical synthesis and analysis systems. Since January 2003, he has been an Associate Professor with the Department of Electrical Engineering, Mathematics and Informatics at the University of Twente, The Netherlands, with the Biosensors/Lab-on-a-Chip Group. He has published over 60 reviewed journal papers on various topics in materials science, microfabrication, and microfluidics.

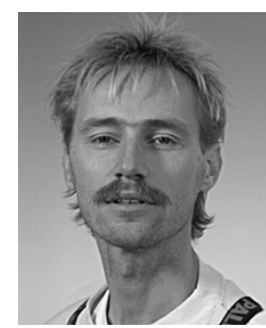

Henri V. Jansen received the M.Sc. degree in electronic engineering and the $\mathrm{Ph} . \mathrm{D}$. degree in electronic engineering from the University of Twente, The Netherlands, in 1991 and 1996, respectively.

After working for half a year at CSEM, Neuchâtel, Switzerland, as a Plasma Engineer, he rejoined the Department of Electrical Engineering at the University of Twente, The Netherlands, as a Postdoctoral researcher. In 2000, he joined IMEC, Leuven, Belgium, to assist in the development of RF MEMS to be used in cellular phones. Since September 2001, he is Assistant Professor at the Department of Electrical Engineering at the University of Twente, The Netherlands. His main research expertise is in silicon-based micromachining, in general, and plasma engineering, in particular, with applications in the field of miniaturized sensor and actuator systems.

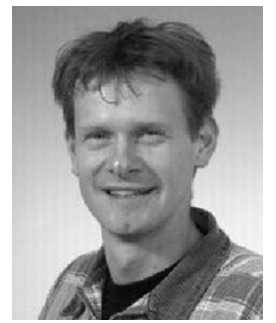

J. W. (Erwin) Berenschot was born on December 13, 1967, in Winterswijk, The Netherlands. He received the B.Sc. degree in applied physics from the Technische Hogeschool Enschede in 1990

Since 1992, he is employed at the Transducers Science and Technology group of the MESA ${ }^{+}$Research Institute. His main research area is fabrication technology with emphasis on development and characterization of etching and deposition techniques for the fabrication of microsystems.

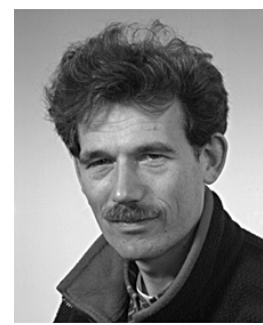

Meint J. de Boer was born on February 2 in Heerenveen, The Netherlands. He received the B.Sc. degree in chimical engineering.

He joined the Company SENTRON in 1982 as a Process Engineer, where he worked in the field of $\mathrm{pH}$-sensors and pressure sensors for medical applications. In 1988, he joined the University of Groningen at the Department of Applied Physics. He focused on nano-engineering for fundamental research on superconductivity. In 1992, he joined the Transducer Science Technology Group at the University of Twente. His current research interests include micromachining fabrication technology and dry etching techniques. He has published over 20 reviewed journal papers on micromachining and related topics and has three patent applications.

J. H. (Rik) de Boer received the B.Sc. degree in mechanical engineering at the Hofstede MTS in Hengelo in 1989.

Since than he has worked for several companies, specializing in the field of fine-mechanics. He gained cleanroom experience with the production of uranium enrichment centrifuges and the production and development of micro-filtration membranes. Since 2002, he has been with the Transducer Science and Technology Group where he works as cleanroom technician in the MESA ${ }^{+}$ facilities. 


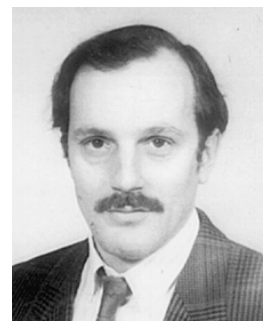

Cees J. M. van Rijn received the physics degree from the Vrije Universiteit of Amsterdam, The Netherlands, in 1982 and the Ph.D. degree in nuclear magnetic relaxation of polyelectrolyte solutions from the University of Leiden, The Netherlands, in 1986.

After graduation, he worked as Scientific Engineer at Philips Eindhoven, The Netherlands, and has special expertise in semiconductor technology, physical and chemical evaporation techniques, and wet and dry chemical etching. In 1993, he has founded Aquamarijn Micro Filtration and he has performed research on microfiltration membranes at the MESA Research Institute, University of Twente, The Netherlands.

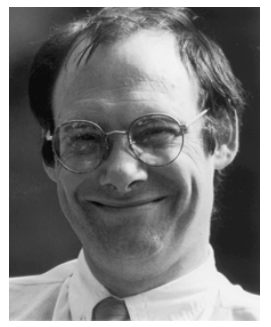

Miko C. Elwenspoek was born on December 9, 1948, Eutin, Germany. He received the degree in physics at the Free University of Berlin (West). His Master's thesis dealt with Raleigh scattering from liquid glycerol using light coming from a Mössbauer source. From 1977 to 1979, he worked with Prof. Helfrich on lipid double layers. In 1979, he started his Ph.D. work with Prof. Quitmann on the subject: relaxation measurements on liquid metals and alloys, in particular alkali metal alloys. In 1983, he received the Ph.D. degree at the Freie Universität Berlin.

In the same year, he moved to Nijmegen, The Netherlands, to study crystal growth of organic crystals in the group of Prof. Bennema of the University of Nijmegen. In 1987, he went to the University of Twente, The Netherlands, to take charge of the micromechanics group of the Sensors and Actuators Laboratory, now called the MESA Research Institute. Since then his research focused on microelectromechanical systems, such as design and modeling of micropumps, resonant sensors, and electrostatic microactuators for microrobots. Fabrication techniques such as the physical chemistry of wet-chemical anisotropic etching, reactive ion etching, wafer bonding, chemical-mechanical polishing and the materials science of various thin films have been his area of interest. Since 1996, he has been employed as a full Professor at the Transducer Technology group at the Faculty of Electrical engineering of the University of Twente. 